University of Nebraska - Lincoln

DigitalCommons@University of Nebraska - Lincoln

\title{
Comparison of nucleic acid extraction platforms for detection of select biothreat agents for use in clinical resource limited settings
}

\author{
Michelle A. Shipley \\ US Army Medical Research Institute of Infectious Diseases \\ Jeffrey W. Koehler \\ US Army Medical Research Institute of Infectious Diseases \\ David A. Kulesh \\ US Army Medical Research Institute of Infectious Diseases \\ Timothy D. Minogue \\ US Army Medical Research Institute of Infectious Diseases
}

Follow this and additional works at: https://digitalcommons.unl.edu/usarmyresearch

Shipley, Michelle A.; Koehler, Jeffrey W.; Kulesh, David A.; and Minogue, Timothy D., "Comparison of nucleic acid extraction platforms for detection of select biothreat agents for use in clinical resource limited settings" (2012). US Army Research. 224.

https://digitalcommons.unl.edu/usarmyresearch/224

This Article is brought to you for free and open access by the U.S. Department of Defense at DigitalCommons@University of Nebraska - Lincoln. It has been accepted for inclusion in US Army Research by an authorized administrator of DigitalCommons@University of Nebraska - Lincoln. 


\title{
Comparison of nucleic acid extraction platforms for detection of select biothreat agents for use in clinical resource limited settings
}

\author{
Michelle A. Shipley, Jeffrey W. Koehler, David A. Kulesh, Timothy D. Minogue* \\ Diagnostic Systems Division, US Army Medical Research Institute of Infectious Diseases, 1425 Porter Street, Fort Detrick, MD, USA
}

\section{A R T I C L E I N F O}

\section{Article history:}

Received 7 May 2012

Received in revised form 14 June 2012

Accepted 14 June 2012

Available online 29 June 2012

\section{Keywords:}

Nucleic acid extraction comparison

Biothreat diagnostics

Field diagnostics

\begin{abstract}
A B S T R A C T
High-quality nucleic acids are critical for optimal PCR-based diagnostics and pathogen detection. Rapid sample processing time is important for the earliest administration of therapeutic and containment measures, especially in the case of biothreat agents. In this context, we compared the Fujifilm QuickGene-Mini80 to Qiagen's QIAamp Mini Purification kits for extraction of DNA and RNA for potential use in austere settings. Qiagen (QIAamp) column-based extraction is the currently recommended purification platform by United States Army Medical Research Institute for Infectious Diseases for both DNA and RNA extraction. However, this sample processing system requires dedicated laboratory equipment including a centrifuge. In this study, we investigated the QuickGene-Mini80, which does not require centrifugation, as a suitable platform for nucleic acid extraction for use in resource-limited locations. Quality of the sample extraction was evaluated using pathogen-specific, real-time PCR assays for nucleic acids extracted from viable and $\gamma$-irradiated Bacillus anthracis, Yersinia pestis, vaccinia virus, Venezuelan equine encephalitis virus, or B. anthracis spores in buffer or human whole blood. QuickGene-Mini80 and QIAamp performed similarly for DNA extraction regardless of organism viability. It was noteworthy that $\gamma$-irradiation did not have a significant impact on real-time PCR for organism detection. Comparison with QIAamp showed a less than adequate performance of the Fujifilm instrument for RNA extraction. However, QuickGene-Mini80 remains a viable alternative to QIAamp for DNA extraction for use in remote settings due to extraction quality, time efficiency, reduced instrument requirements, and ease of use.
\end{abstract}

Published by Elsevier B.V.

\section{Introduction}

Biothreat agents, including Bacillus anthracis, Yersinia pestis, Variola virus (vaccinia virus is a surrogate for Variola virus, the causative agent of smallpox), and Venezuelan equine encephalitis virus (VEEV), represent significant public health risks due to high pathogenicity and potential for aerosolization (Roy et al., 2010). Rapid and specific identification of these pathogens is critical for initiation of appropriate containment and therapeutic measures as prognosis is directly impacted by time to diagnosis. This is especially true for the potential of an intentional release of a biological agent. In this context, real-time PCR is currently implemented for the highly specific identification of pathogens in both clinical and environmental settings (Belgrader et al., 1998; Christensen et al., 2006; Higgins et al., 1998; Makino et al., 2001; Ryu et al., 2003; Shchelkunov et al., 2011; Skottman et al., 2007; Tomaso et al., 2008).

Numerous factors inherent to clinical and environmental matrices can inhibit downstream molecular diagnostic applications, such as real-time PCR (Rossen et al., 1992; Wilson, 1997). The quality of the

\footnotetext{
* Corresponding author at: USAMRIID, DSD, 1425 Porter Street, Fort Detrick, MD, 21702, USA. Tel.: +1 301619 6352; fax: +13016192492.

E-mail address: timothy.minogue@us.army.mil (T.D. Minogue).
}

nucleic acids purified from a clinical or environmental sample is critical for the optimal performance of these types of assays. This purification step is especially important for diagnostic pathogen detection where sensitivity is critical. Specific inhibitors of real-time PCR diagnostics include hemoglobin (Akane et al., 1994) and polysaccharides (Monteiro et al., 1997) from blood as well as proteins from food samples (Rossen et al., 1992) and humic and fulvic acids (Tsai and Olson, 1992) from environmental samples. Beyond inhibitor removal, release of target DNA/RNA is requisite for optimal molecular assay kinetics. For bacteria and spores, efficient lysis of the cell wall is needed; however, these harsh lysing conditions must be tempered to maintain the integrity of the extracted nucleic acids (Rantakokko-Jalava and Jalava, 2002). Because of all these factors, most diagnostic applications of real-time PCR are accompanied by sample processing and nucleic acid extraction.

Our lab has extensive experience using Qiagen's QIAamp Mini Extraction Kits for DNA and RNA extraction of biothreat organisms. These platforms perform well for extraction of clinical and environmental samples; however, the extraction protocols used require capital investment in equipment (ex. a centrifuge) as well as time for processing $(90+\min )$. While these kits are adequate for reference laboratory use, this study sought to evaluate additional extraction platforms that could yield similar results to the tested Qiagen kits 
but required less resources and potentially could reduce the time-toanswer. In this context, we evaluated Fujifilm's QuickGene-Mini80 (QG-Mini80) platform as a possible solution in comparison to QIAamp. To test the applicability of the QG-Mini80 for clinical biothreat agent detection, nucleic acids were isolated from buffer and human whole blood containing the serially diluted biothreat agents B. anthracis, $Y$. pestis, vaccinia virus (VACV), and VEEV as well as B. anthracis spores. Established real-time PCR-based assays were conducted to compare purification efficacies as well as agent detectability from the extracted nucleic acids.

\section{Materials and methods}

\subsection{Bacterial and viral strains}

Biothreat organisms maintained at United States Army Medical Research Institute for Infectious Diseases (USAMRIID) or purchased through the Critical Reagents Program (CRP, Frederick, MD), a reagents resource for biodefense research, were used for these studies. Viable or $\gamma$-irradiated bacteria included B. anthracis Ames strain vegetative cells and $Y$. pestis strain $\mathrm{CO} 2$ bacteria as well as $\gamma$-irradiated $B$. anthracis Ames strain spores. Viruses included viable VACV strain SALK 17633, $\gamma$-irradiated VACV strain Elstree/Lister, and viable or $\gamma$-irradiated VEEV strain Trinidad donkey (IA/IB).

Organism was diluted into the appropriate matrix, either buffer [Dulbecco's phosphate-buffered saline (PBS)] or human whole blood (Bioreclamation, NY), to generate a stock, and this stock was then serially diluted in the same matrix. B. anthracis Ames strain spores were diluted into molecular grade water to prevent clumping, and concentrations of viable spores were determined using sheep blood agar plates (Remel, Lenexa, KS) incubated at $37{ }^{\circ} \mathrm{C}$ for $24 \mathrm{~h}$. From this stock, serial dilutions of spores in water were made, and diluted spores were sonicated using the Branson 2510 Ultrasonic Cleaner (Danbury, CT). Previously quantified $\gamma$-irradiated spores were diluted into molecular grade water and sonicated, and serial dilutions into molecular grade water were made.

\subsection{Fujifilm QuickGene-Mini80 platform}

DNA from the diluted organisms or spores was isolated using the QG-Mini80 DNA Tissue Kit. The manufacturer's instructions were modified from the recommended protocol. Specifically, microcentrifuge tubes containing $100 \mu \mathrm{l}$ of sample (organism diluted in buffer or blood), $180 \mu \mathrm{l}$ of lysis buffer (contains guanidine hydrochloride), and $20 \mu \mathrm{l}$ of proteinase $\mathrm{K}$ were mixed and incubated for $2 \mathrm{~min}$ at $55{ }^{\circ} \mathrm{C}$. After this incubation, $200 \mu \mathrm{l}$ of ethanol (>99\%) was added and mixed, and the sample was applied to the column. Samples were washed three times with wash buffer, and DNA was subsequently eluted in $100 \mu \mathrm{l}$ of elution buffer after a $90 \mathrm{sec}$ incubation at room temperature. VEEV RNA was extracted using the QG-Mini80 RNA Tissue Kit S II. Microcentrifuge tubes containing $70 \mu \mathrm{l}$ of sample and $35 \mu \mathrm{l}$ of buffer SRT were combined. Thirty-five $\mu \mathrm{l}$ of ethanol ( $>99 \%$ ) was added to the lysate, mixed, and the sample was applied to the cartridge with three subsequent washes of buffer WRT. RNA was eluted in $100 \mu \mathrm{l}$ of buffer CRT after a $120 \mathrm{sec}$ incubation at room temperature.

\subsection{Qiagen QIAamp mini platform}

DNA from the serially diluted organisms was manually isolated using Qiagen's DNA mini platform with modifications to manufacturer's instructions. Specifically, microcentrifuge tubes containing $100 \mu \mathrm{l}$ of sample, $80 \mu \mathrm{l}$ of PBS, $200 \mu \mathrm{l}$ of buffer AL (contains guanidine hydrochloride), and $20 \mu \mathrm{l}$ of proteinase $\mathrm{K}(17.8 \mathrm{mg} / \mathrm{ml})$ were combined and incubated at $55{ }^{\circ} \mathrm{C}$ for $60 \mathrm{~min}$. After this incubation, $210 \mu \mathrm{l}$ of ethanol (>99\%) was added. Samples were vortexed and loaded onto a Qiagen spin column for centrifugation followed by washing with buffers AW1 and AW2. After centrifugation to dry the samples, DNA was eluted for $5 \mathrm{~min}$ at $70{ }^{\circ} \mathrm{C}$ using $100 \mu$ of preheated AE buffer (10 mM Tris-CL, $0.5 \mathrm{mM}$ EDTA, pH 9.0). VEEV RNA from a $70 \mu \mathrm{l}$ sample was extracted using Qiagen's QIAamp RNA Blood Mini Kit according to the manufacturer's instructions.

\subsection{Extraction efficiency measurement}

In order to compare the extraction efficiencies for both platforms, $\gamma$-irradiated $B$. anthracis vegetative cells were serially diluted $1: 10$ in buffer from $1 \times 10^{7}$ to $1 \times 10^{4}$ colony forming units (CFU)/sample. DNA was extracted from each sample in triplicate using either the QIAamp DNA Mini kit or the QG-Mini80 DNA extraction kit. DNA was quantified in triplicate, one sample per extraction for a total of three replicates, using the Quant-iT PicoGreen dsDNA Reagent (Life Technologies, Grand Isle, NY) according to the manufacturer's instructions. Statistical significance in DNA extraction for each platform was evaluated using a two-tail $t$-test at each sample dilution, assuming equal variance.

\subsection{Evaluation of the extracted material by agent-specific real-time PCR}

All samples were evaluated for successful PCR amplification via real-time PCR using the R.A.P.I.D. thermocycler (Idaho Technology, Inc., Salt Lake City, UT). Five $\mu$ ls of extracted nucleic acids were used for each PCR reaction in a $20 \mu \mathrm{l}$ reaction volume. For all of the DNA-extracted organisms, the cycling conditions were 45 cycles of $95{ }^{\circ} \mathrm{C}$ for $0 \mathrm{~s}$ and $60{ }^{\circ} \mathrm{C}$ for $20 \mathrm{~s}$. DNA extracted from B. anthracis Ames was detected using a pX01-specific assay as previously described (Christensen et al., 2006). Y. pestis was detected using a PIMspecific assay as previously described (Christensen et al., 2006). VACV primers targeting the polymerase were used at a final concentration of $0.5 \mathrm{mM}$ for VACA25L-F151 (5'-CACCTCCACCAAAACCTAAAACTC) and VACA25L-R231 (5'-AAAATgggCgTggATTgTTAAC). VACV probe VACA25L-p193S-MGB (5'-AgACgTCCgATTCTAT) was used at $0.1 \mathrm{mM}$. VEEV was detected using primers and probe targeting nsp2 (Parker et al., 2010). Primers VEENSP2U (5'-CTTggCAAACCTCTggCAgC) and VEENSP2L (5'-ATACCCACTCggTTCCAgCg) were used at a final concentration of $0.9 \mathrm{mM}$, and probe VEENSP2P1A (5'-CTCTTCATgCAATgCC CTTCTCCTgTCA) was used at a final concentration of $0.06 \mathrm{mM}$. For VEEV, the cycling conditions included a reverse transcriptase step of $50{ }^{\circ} \mathrm{C}$ for 15 min followed by a 5 -min hold at $95{ }^{\circ} \mathrm{C}$ and 45 cycles of $95{ }^{\circ} \mathrm{C}$ for $0 \mathrm{~s}, 60^{\circ} \mathrm{C}$ for $20 \mathrm{~s}$ using the SuperScript One-Step RT-PCR system (Life Technologies, Grand Island, NY) supplemented with $0.25 \mathrm{mM}$ BSA (Sigma-Aldrich, St. Louis, MO). All probes were labeled with FAM/ TAMRA. A real-time PCR sample was considered positive if the $C_{T}$ value was $<40$ cycles. Negative results were noted if the number of cycles were $>40$ or if no $C_{T}$ was observed. If any fluorescence was observed for the no template control (NTC), the run was considered invalid.

For each analysis, we correlated real-time PCR $C_{T}$ values to the relative concentration of target, thus lower $C_{T}$ values correlated to an increase in target material. For each sample, three separate extractions were conducted, and nucleic acids were quantified in triplicate with one replicate coming from each extraction. The limit of detection (LOD) or lowest amount of pathogen detectable was determined to be the target organism concentration where all three extracted samples resulted in a positive result by real-time PCR.

\section{Results}

\subsection{Platform ease of use, general characteristics, and extraction efficiencies}

Initial evaluations focused on assessing general physical and fiscal parameters as well as defining any differences in extraction efficiency between the QG-Mini80 and QIAamp using B. anthracis DNA extractions. For the QG-Mini80, up to eight samples could be extracted in 


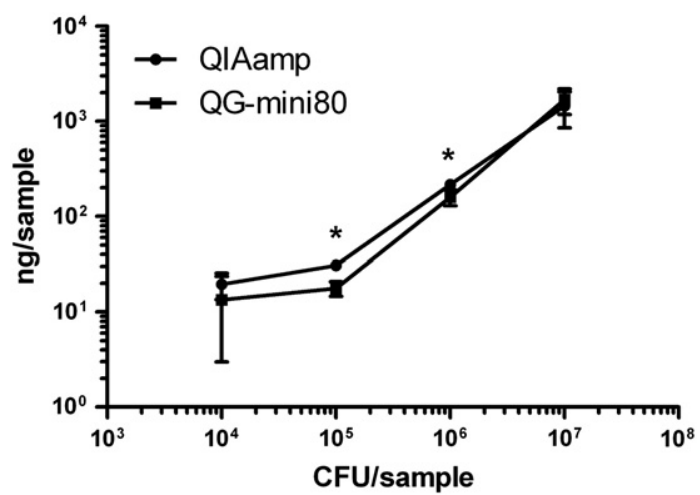

Fig. 1. Comparison of the amount of DNA recovered following serial dilution of $\gamma$-irradiated B. anthracis in buffer. Triplicate serial dilutions of $\gamma$-irradiated $B$. anthracis in buffer were purified with either the QG-Mini80 or the QIAamp DNA extraction kit. The amount of DNA recovered was quantified (one sample per replicate) using the Quant-iT PicoGreen dsDNA reagent. Statistical differences were measured using a $t$-test, and $*$ is a $p$ value of $<0.05$.

approximately $15-20 \mathrm{~min}$, compared to $108 \mathrm{~min}$ for 16 samples using the QIAamp DNA extraction kit. Averaged times were based on $48 \mathrm{~B}$. anthracis DNA extractions. With regard to cost, both platforms are similarly priced per sample at USD $\$ 2.60$ for the QGMini80 and \$2.45 for the QIAamp DNA extraction kit. Overall, QIAamp showed slightly better DNA recovery compared to QG-Mini80, with statistically significant differences at the $10^{5}(\mathrm{p}=0.010)$ and the $10^{6}(\mathrm{p}=0.04)$ CFU dilutions (Fig. 1$)$. Beyond these variations in extraction efficiency, the principal difference noted from these data was the time of extraction, with QIAamp taking an average of about 90 min longer than QG-Mini80 over the course of 48 samples. A comparison of the extraction efficiency for RNA was also performed using the Quant-iT RiboGreen RNA Reagent and Kit (Life Technologies), but the sensitivity of the RiboGreen kit was insufficient to detect the level of input RNA used in this study (data not shown). During this evaluation and all subsequent analyses, we did not observe cross-contamination between the samples with either platform; none of the negative control reactions produced false positive results.

\subsection{DNA and RNA extraction from buffer and blood using $\gamma$-irradiated pathogen}

The lowest amount of detectable pathogen was determined for each $\gamma$-irradiated pathogen in buffer in order to optimize the QG-Mini80 protocol and initially evaluate the quality of the extracted nucleic acids from phylogenetically diverse biothreat agents (Table 1). Buffer was used for this initial evaluation as it is a simple matrix and contains limited inhibitors of PCR. Pathogen-specific real-time PCR assays were used to assess extraction efficiencies, comparing the $C_{T}$ values at different pathogen dilutions. Results from this comparison varied and suggested better extraction efficiency with QIAamp. For example, the LOD for $\gamma$-irradiated $Y$. pestis was $50 \mathrm{CFU} / \mathrm{ml}$ for both platforms; however, $\mathrm{C}_{\mathrm{T}}$ values for the QIAamp-extracted DNA were one to two cycles earlier. Positive samples were detected in two of the three samples at the next lower dilution, $10 \mathrm{CFU} / \mathrm{ml}$ (Table 1). Similarly, LODs for VACV (DNA) and VEEV (RNA) were lower for QIAamp [at $5 \times 10^{2}$ and $1 \times 10^{3}$ plaque forming units $(\mathrm{PFU}) / \mathrm{ml}$, respectively] than QG-Mini80 (at $5 \times 10^{3}$ for both viruses) extracted material. Interestingly, the QG-Mini80 extracted material resulted in a lower amount of detectable pathogen, $50 \mathrm{CFU} / \mathrm{ml}$, for $B$. anthracis Ames vegetative cells than the QIAamp at $100 \mathrm{CFU} / \mathrm{ml}$ (Table 1).

Defining the clinical and diagnostic applicability of the QG-Mini80 platform was another central objective for this research. To test this aspect, both QG-Mini80 and QIAamp were evaluated for extraction efficiency using $\gamma$-irradiated organism spiked into human whole blood as a representative clinical matrix. Similar to observations in buffer, QIAamp-purified material from blood showed better detectability than similar samples extracted using the QG-Mini80 for all agents tested with the exception of VACV (Table 1). In this case, both platforms yielded similar amounts of detectable VACV nucleic acid at $5 \times 10^{2} \mathrm{PFU} /$ $\mathrm{ml}$; however, the $\mathrm{C}_{\mathrm{T}}$ value for the QIAamp extracted material was two cycles lower than the QG-Mini80 extracted material. Furthermore, for QIAamp's B. anthracis extraction, the detectable amount of DNA was lower than the QG-Mini80 (50 and $100 \mathrm{CFU} / \mathrm{ml}$, respectively) even though two of three samples were positive at $50 \mathrm{CFU} / \mathrm{ml}$ for the QG-Mini80-extracted material. Overall, the buffer and whole blood data suggested better extraction efficiency for QIAamp purification compared to QG-Mini80.

\subsection{DNA and RNA extraction from buffer and blood using viable pathogen}

Evaluations with $\gamma$-irradiated biothreat agents suggested that the QIAamp performed slightly better using the assessed real-time PCR assays; however, this analysis did not address any impact the irradiation process may have had on the nucleic acid material before extraction. To assess if the QG-Mini80 and QIAamp protocols might perform differently with non-irradiated material, we evaluated serially diluted viable organisms in human whole blood (Table 2). Both platforms yielded similar detectable amounts of nucleic acid for $Y$. pestis at $5 \times 10^{1} \mathrm{CFU} / \mathrm{ml}$ and VACV at $5 \times 10^{2} \mathrm{PFU} / \mathrm{ml}$ (Table 2). QG-Mini80 performed better than QIAamp at extracting viable B. anthracis from whole blood, with detectable nucleic acid from 50 to $5 \times 10^{2} \mathrm{CFU} / \mathrm{ml}$, respectively. These results were significantly contrasted by results with viable VEEV. After several evaluations with two different viral stocks and at titers of $1 \times 10^{6} \mathrm{PFU} / \mathrm{ml}$, the QG-Mini80 was unable to consistently extract detectable levels of VEEV RNA (Table 2 and data not shown).

\subsection{Evaluation of extraction platforms for spore DNA isolation}

The overall trend of lower sensitivities with QG-Mini80 suggested this method may not be adequate for extracting some of the more recalcitrant biothreat samples. To test this hypothesis, we evaluated DNA extraction on both platforms followed by real-time PCR for $\gamma$-irradiated and viable $B$. anthracis spores serially diluted in water.

Table 1

Real-time PCR based $\left(\mathrm{C}_{\mathrm{T}}\right)$ evaluation of the QuickGene-Mini80 and QIAamp purification platforms of $\gamma$-irradiated biothreat agents diluted in buffer and whole blood.

\begin{tabular}{|c|c|c|c|c|c|}
\hline \multirow[t]{2}{*}{ Organism } & \multirow{2}{*}{$\begin{array}{l}\mathrm{CFU} / \\
\mathrm{PFU} / \mathrm{ml}\end{array}$} & \multicolumn{2}{|c|}{$\mathrm{C}_{\mathrm{T}}$ values for QG-Mini80 ${ }^{\mathrm{a}}$} & \multicolumn{2}{|c|}{$\mathrm{C}_{\mathrm{T}}$ values for QIAamp ${ }^{\mathrm{a}}$} \\
\hline & & Buffer & Blood & Buffer & Blood \\
\hline \multirow[t]{5}{*}{ B. anthracis } & 1000 & $30.21 \pm 0.43$ & $31.70 \pm 0.23$ & $30.73 \pm 0.55$ & $30.17 \pm 0.32$ \\
\hline & 500 & $33.10 \pm 0.39$ & $31.66 \pm 0.18$ & $31.81 \pm 0.45$ & $30.73 \pm 0.46$ \\
\hline & 100 & $35.15 \pm 0.49$ & $33.13 \pm 0.47$ & $34.79 \pm 0.44$ & $33.08 \pm 0.20$ \\
\hline & 50 & $35.92 \pm 0.91$ & $33.68^{\mathrm{b}}$ & $34.51^{\mathrm{b}}$ & $33.15 \pm 0.75$ \\
\hline & 10 & $37.43^{c}$ & $33.56^{c}$ & $37.32^{c}$ & $33.40^{\mathrm{b}}$ \\
\hline \multirow[t]{5}{*}{ Y. pestis } & 1000 & $30.44 \pm 0.34$ & $30.41 \pm 0.73$ & $28.97 \pm 0.43$ & $29.13 \pm 0.23$ \\
\hline & 500 & $31.97 \pm 0.59$ & $31.90 \pm 0.33$ & $29.94 \pm 0.33$ & $30.35 \pm 0.39$ \\
\hline & 100 & $33.42 \pm 0.81$ & $34.16 \pm 0.98$ & $32.59 \pm 0.07$ & $32.94 \pm 0.53$ \\
\hline & 50 & $34.95 \pm 0.35$ & $34.46 \pm 0.96$ & $34.02 \pm 0.50$ & $33.78 \pm 0.92$ \\
\hline & 10 & nd & $36.06^{\mathrm{b}}$ & $36.50^{\mathrm{b}}$ & $35.74 \pm 0.78$ \\
\hline \multirow[t]{5}{*}{$V A C V$} & 50,000 & $31.20 \pm 0.06$ & $27.29 \pm 0.86$ & $29.93 \pm 0.18$ & $25.37 \pm 2.12$ \\
\hline & 10,000 & $33.83 \pm 0.45$ & $30.35 \pm 0.47$ & $32.67 \pm 0.30$ & $28.60 \pm 0.53$ \\
\hline & 5000 & $35.48 \pm 1.67$ & $31.78 \pm 0.47$ & $33.25 \pm 0.39$ & $29.22 \pm 0.22$ \\
\hline & 1000 & $36.58^{c}$ & $34.64 \pm 0.22$ & $35.72 \pm 1.31$ & $32.82 \pm 0.51$ \\
\hline & 500 & $37.49^{\mathrm{b}}$ & $34.92 \pm 1.40$ & $35.87 \pm 0.62$ & $32.85 \pm 0.41$ \\
\hline \multirow[t]{4}{*}{ VEEV } & 50,000 & $30.93 \pm 0.97$ & $32.42 \pm 0.16$ & $29.14 \pm 0.17$ & $28.16 \pm 0.22$ \\
\hline & 10,000 & $31.71 \pm 1.06$ & $32.35 \pm 0.83$ & $30.82 \pm 1.81$ & $29.52 \pm 0.69$ \\
\hline & 5000 & $32.93 \pm 0.26$ & nd & $31.97 \pm 0.07$ & $31.17 \pm 0.53$ \\
\hline & 1000 & $32.39^{\mathrm{c}}$ & nd & $32.91 \pm 0.18$ & $31.56 \pm 0.63$ \\
\hline
\end{tabular}

\pm is the standard deviation of one real-time PCR assay from three replicates; nd = not detected.

a A positive sample had a $C_{T}$ value $<40$ cycles, and a negative sample had a $C_{T}$ value of $>40$ cycles.

b Two of three replicates gave valid results.

c One of three replicates gave valid results. 
Table 2

Real-time PCR based $\left(C_{T}\right)$ evaluation of the QuickGene-Mini80 and QIAamp purification platforms of viable biothreat agents in whole blood.

\begin{tabular}{lrll}
\hline Organism & CFU/PFU/ml & $\mathrm{C}_{\mathrm{T}}$ values for QG-Mini80 & $\mathrm{C}_{\mathrm{T}}$ values for QIAamp $^{\mathrm{a}}$ \\
\hline B. anthracis & 1000 & $30.09 \pm 0.15$ & $31.18 \pm 0.78$ \\
& 500 & $32.08 \pm 0.27$ & $31.37 \pm 0.07$ \\
& 100 & $33.41 \pm 0.78^{\mathrm{b}}$ & nd \\
Y. pestis & 50 & $33.67 \pm 0.79$ & nd \\
& 1000 & $30.17 \pm 0.45$ & $30.00 \pm 0.20$ \\
& 500 & $31.72 \pm 0.19$ & $31.56 \pm 0.50$ \\
VACV & 100 & $35.30 \pm 1.75$ & $34.01 \pm 0.29$ \\
& 50 & $35.54 \pm 0.87$ & $36.46 \pm 0.60$ \\
& 10,000 & $25.79 \pm 1.13$ & $25.30 \pm 0.87$ \\
VEEV & 5000 & $27.33 \pm 0.29$ & $25.98 \pm 0.94$ \\
& 1000 & $29.86 \pm 0.83$ & $28.27 \pm 0.50$ \\
& 500 & $30.85 \pm 0.19$ & $29.65 \pm 1.68$ \\
& 50,000 & nd & $27.94 \pm 0.84$ \\
& 10,000 & nd & $30.22 \pm 1.21$ \\
& 5000 & $35.37^{\mathrm{b}}$ & $29.60 \pm 3.71$ \\
& 1000 & nd & $32.97 \pm 1.50$
\end{tabular}

\pm is the standard deviation of one real-time PCR assay from three replicates; $n d=$ not detected.

a $A$ positive sample had a $C_{T}$ value $<40$ cycles, and a negative sample had a $C_{T}$ value of $>40$ cycles.

b Two of three replicates gave valid results.

The lowest amount of detectable spore material extracted with QIAamp was $5 \times 10^{2} \mathrm{CFU} / \mathrm{ml}$ compared to $5 \times 10^{3} \mathrm{CFU} / \mathrm{ml}$ with the QG-Mini80, supporting this hypothesis (Table 3 ). Data with viable $B$. anthracis Ames spores showed a similar trend, although with less of a disparity between the detectable amounts of input spores.

\section{Discussion}

In the event of an infection with an unknown agent, rapid pathogen detection is critical for containment and efficacious treatment. For diagnostics and real-time PCR detection of etiologic agents, our current standard extraction methods are Qiagen QIAamp DNA Mini Kit and QIAamp Blood RNA Mini Kit. These platforms utilize chaotropic lysis and silica-gel based nucleic acid binding using centrifugation for sample binding, washing, and nucleic acid elution. While this method yields excellent nucleic acids, the process is time consuming (approximately $2 \mathrm{~h}$ from sample to extracted material) and requires equipment, such as a centrifuge, that limits the use of these platforms in resource-limited settings. Fujifilm's QG-Mini80 platform for DNA and RNA extraction is a potential alternative to QIAamp for nucleic acid extraction. Rose et al. recently described the QG-Mini80, along with the Instagene Only (Bio-Rad, Hercules, CA), as the easiest to use among 8 different methods they evaluated for Bacillus atrophaeus

Table 3

Real-time PCR based $\left(C_{\mathrm{T}}\right)$ evaluation of the QuickGene-Mini80 and QIAamp purification platforms for $B$. anthracis spores in water.

\begin{tabular}{lrll}
\hline Organism & CFU/ml & $\mathrm{C}_{\mathrm{T}}$ values for QG-Mini80 & $\mathrm{C}_{\mathrm{T}}$ values for QIAamp $^{\mathrm{a}}$ \\
\hline B. anthracis & 10,000 & $32.78 \pm 0.32$ & $30.41 \pm 1.50$ \\
$(\gamma$-irradiated $)$ & 5000 & $34.93 \pm 2.04$ & $31.25 \pm 0.57$ \\
& 1000 & $34.81^{\mathrm{b}}$ & $34.71 \pm 2.39$ \\
& 500 & $\mathrm{nd}$ & $34.69 \pm 0.84$ \\
B. anthracis & 10,000 & $34.32 \pm 1.37$ & $30.85 \pm 0.57$ \\
(viable) & 5000 & $34.85^{\mathrm{b}}$ & $32.57 \pm 1.20$ \\
& 1000 & $37.08^{\mathrm{c}}$ & $34.20^{\mathrm{c}}$ \\
& 500 & $37.72^{\mathrm{c}}$ & $35.65^{\mathrm{c}}$ \\
\hline
\end{tabular}

\pm is the standard deviation of one real-time PCR assay from three replicates; nd = not detected.

a A positive sample had a $C_{T}$ value $<40$ cycles, and a negative sample had a $C_{T}$ value of $>40$ cycles.

b Two of three replicates gave valid results.

c One of three replicates gave valid results. spore DNA extraction (Rose et al., 2011). This technology utilizes similar chaotropic lysis and a thin, silica-based membrane for nucleic acid extraction but, instead of centrifugation, uses positive pressure for sample application, membrane washing, and elution. Additionally, the QG-Mini80 has short sample processing time (approximately 15-20 min for eight samples), a small footprint, greater ease of use, and minimal power requirements. The objective of this research was to assess the QG-Mini80 platform for the quality of nucleic acid extraction within a clinical context for use in austere settings.

Comparison of the extraction efficiencies suggested a trend of better yields for the QIAamp DNA Mini Kit compared to QG-Mini80, especially at lower target DNA concentrations. This could be the result of several differences between the platforms, including membrane size and different lysing/binding/washing chemistries. The QG-Mini80 filter is approximately $80 \mu \mathrm{m}$ in thickness compared to the typical silica membrane of up to $1000 \mu \mathrm{m}$. While Fujifilm advertises equivalent surface area due to the porosity of its membrane, the reduced DNA recovery for the QG-Mini80 suggests either a reduced binding potential compared to the canonical spun glass fiber columns of QIAamp or a less efficient processing, i.e. lysis of the sample or removal of PCR inhibitors. Regardless of the specific reasons for the reduced DNA recovery, this did not directly correlate to less effective detection of the extracted material. This is demonstrated with viable B. anthracis in a clinical matrix where overall sensitivity in downstream PCR reactions was better with QG-Mini80 extractions compared to QIAamp. It is possible that a more comprehensive study comparing QG-Mini80 and QIAamp might show more difference or similarity in the detectability of extracted materials; however, the presented data show the QG-Mini80 is suitable for use in remote environments in the clinical arena for DNA-based organisms. In general, QG-Mini80 and QIAamp resulted in roughly comparable sensitivities for the extracted material with cross-platform differences being only 1-log, and more often a 1/2-log, in disparity for DNA-based organisms.

Similar results were observed by Rose et al., who compared 8 different DNA extraction platforms for extraction efficiency using powder, liquid, solid, and swabs as the matrix type. While QIAamp was not evaluated in this study, the QG-Mini80 performed acceptably (ranked 6/8 of platforms across the sample types) (Rose et al., 2011). The QG-Mini80 also performed acceptably for extracting detectable nucleic acid within clinically relevant ranges in this study. This statement is contrasted by data presented here; RNA-based and spore-forming organisms require more detailed optimization and investigation before recommended field use.

Prior to this research, it was unclear whether the irradiation process would detrimentally impact real-time PCR which target smaller amplicons than previous studies have evaluated (Lim et al., 2006; Trampuz et al., 2006). Use of $\gamma$-irradiated biothreat agents in biosafety level 2 as a surrogate for viable agent is highly preferential given the safety precautions required for working with biosafety level $3+$ organisms and the corollary fiscal impact. Comparing data from $\gamma$-irradiated and viable agent extractions suggest marginal impact on extraction efficacy and/or downstream detection. One counterpoint to this statement specific to the QG-Mini80 is the extraction of viable VEEV RNA. Real-time PCR results with $\gamma$-irradiated VEEV showed better extraction for QIAamp; however, while results of the QG-Mini80 were consistent, there were also dramatically lower amounts of detectable RNA extracted for $\gamma$-irradiated compared to QIAamp and non-existent amounts for viable agent. Lack of sufficient extraction results with viable VEEV cannot be attributed to major sample differences as QIAamp extractions were comparable, viable or $\gamma$-irradiated. This may be a specific result to the QG-Mini80 chemistry as this phenomenon has not been observed previously in our lab. Reasons for poor and inconsistent performance with viable VEEV could be attributed to a variety of factors, but more research with the QG-Mini80 is required to draw any proper conclusions. 
The QG-Mini80's flexibility, portability, ease of use, and time-toanswer are all considerations that make this instrument an attractive alternative to column-based manual extractions. The QG-Mini80 has several advantages over its QIAamp counterpart currently recommended to field users. In 15-20 min, eight samples are ready for PCR, an hour and a half faster than Qiagen. While both procedures utilize affinity chromatography for nucleic acid capture, Qiagen columns are centrifuged and transferred during each wash, dry, and elution step whereas the QG-Mini80 columns are racked and remain stationary, allowing minimal sample handling and no centrifugation. This would be ideal for extraction of DNA-based pathogens where minimal manipulation and aerosol generation are highly desired. In addition, the QG-Mini80 is highly transportable with its compact size of $3 \mathrm{~kg}$ and measurements of $22 \times 28$ in. The principle caveat is the comparative performance. RNA-based purification was unacceptable, however, results with DNA are adequate and within relevant target organism ranges for diagnostic applications.

\section{Acknowledgments}

The authors would like to thank Dr. David A. Norwood for providing the $B$. anthracis, $Y$. pestis, and VEEV real-time assays. The opinions, interpretations, conclusions, and recommendations contained herein are those of the authors and are not necessarily endorsed by the U.S. Army. This research was supported by the Defense Threat Reduction Agency (DTRA) through the Joint Science and Technology Office for Chemical and Biological Defense, grant \# 8.10041_08_RD_B. Author contribution: TDM conceived and designed the experiments, MAS performed the experiments, DAK designed and evaluated the real-time PCR assays, and MAS, JWK, DAK, and TDM analyzed and interpreted the data and wrote the manuscript.

\section{References}

Akane, A., Matsubara, K., Nakamura, H., Takahashi, S., Kimura, K., 1994. Identification of the heme compound copurified with deoxyribonucleic acid (DNA) from bloodstains, a major inhibitor of polymerase chain reaction (PCR) amplification. J. Forensic Sci. 39, 362-372.

Belgrader, P., Benett, W., Hadley, D., Long, G., Mariella Jr., R., Milanovich, F., et al., 1998. Rapid pathogen detection using a microchip PCR array instrument. Clin. Chem. 44, 2191-2194.
Christensen, D.R., Hartman, L.J., Loveless, B.M., Frye, M.S., Shipley, M.A., Bridge, D.L., et al., 2006. Detection of biological threat agents by real-time PCR: comparison of assay performance on the R.A.P.I.D., the LightCycler, and the Smart Cycler platforms. Clin. Chem. 52, 141-145.

Higgins, J.A., Ezzell, J., Hinnebusch, B.J., Shipley, M., Henchal, E.A., Ibrahim, M.S., 1998. 5' Nuclease PCR assay to detect Yersinia pestis. J. Clin. Microbiol. 36, 2284-2288.

Lim, S., Yoon, H., Ryu, S., Jung, J., Lee, M., Kim, D., 2006. A comparative evaluation of radiation-induced DNA damage using real-time PCR: influence of base composition. Radiat. Res. 165, 430-437.

Makino, S.I., Cheun, H.I., Watarai, M., Uchida, I., Takeshi, K., 2001. Detection of anthrax spores from the air by real-time PCR. Lett. Appl. Microbiol. 33, 237-240.

Monteiro, L., Bonnemaison, D., Vekris, A., Petry, K.G., Bonnet, J., Vidal, R., et al., 1997. Complex polysaccharides as PCR inhibitors in feces: Helicobacter pylori model. J. Clin. Microbiol. 35, 995-998.

Parker, M.D., Buckley, M.J., Melanson, V.R., Glass, P.J., Norwood, D., Hart, M.K., 2010. Antibody to the E3 glycoprotein protects mice against lethal Venezuelan equine encephalitis virus infection. J. Virol. 84, 12683-12690.

Rantakokko-Jalava, K., Jalava, J., 2002. Optimal DNA isolation method for detection of bacteria in clinical specimens by broad-range PCR. J. Clin. Microbiol. 40, 4211-4217.

Rose, H.L., Dewey, C.A., Ely, M.S., Willoughby, S.L., Parsons, T.M., Cox, V., et al., 2011. Comparison of eight methods for the extraction of Bacillus atrophaeus spore DNA from eleven common interferents and a common swab. PLoS One 6, e22668.

Rossen, L., Norskov, P., Holmstrom, K., Rasmussen, O.F., 1992. Inhibition of PCR by components of food samples, microbial diagnostic assays and DNA-extraction solutions. Int. J. Food Microbiol. 17, 37-45.

Roy, C.J., Reed, D.S., Hutt, J.A., 2010. Aerobiology and inhalation exposure to biological select agents and toxins. Vet. Pathol. 47, 779-789.

Ryu, C., Lee, K., Yoo, C., Seong, W.K., Oh, H.B., 2003. Sensitive and rapid quantitative detection of anthrax spores isolated from soil samples by real-time PCR. Microbiol. Immunol. 47, 693-699.

Shchelkunov, S.N., Shcherbakov, D.N., Maksyutov, R.A., Gavrilova, E.V., 2011. Speciesspecific identification of variola, monkeypox, cowpox, and vaccinia viruses by multiplex real-time PCR assay. J. Virol. Methods 175, 163-169.

Skottman, T., Piiparinen, H., Hyytiainen, H., Myllys, V., Skurnik, M., Nikkari, S., 2007. Simultaneous real-time PCR detection of Bacillus anthracis, Francisella tularensis and Yersinia pestis. Eur. J. Clin. Microbiol. Infect. Dis. 26, 207-211.

Tomaso, H., Jacob, D., Eickhoff, M., Scholz, H.C., Al Dahouk, S., Kattar, M.M., et al., 2008. Preliminary validation of real-time PCR assays for the identification of Yersinia pestis. Clin. Chem. Lab. Med. 46, 1239-1244.

Trampuz, A., Piper, K.E., Steckelberg, J.M., Patel, R., 2006. Effect of gamma irradiation on viability and DNA of Staphylococcus epidermidis and Escherichia coli. J. Med. Microbiol. 55, 1271-1275.

Tsai, Y.L., Olson, B.H., 1992. Detection of low numbers of bacterial cells in soils and sediments by polymerase chain reaction. Appl. Environ. Microbiol. 58, 754-757.

Wilson, I.G., 1997. Inhibition and facilitation of nucleic acid amplification. Appl. Environ. Microbiol. 63, 3741-3751. 